\title{
Atmospheric Radon-222 Concentration Variation with Height and Time
}

\author{
John E. Pearson ${ }^{1}$ and Harry Moses \\ Argonne National Laboratory, Argonne, Ill. \\ (Manuscript received 10 September 1965, in revised form 1 December 1965)
}

\begin{abstract}
Studies of concentrations of radon-222 in the atmosphere have been made from the surface of the earth to 16 meters elevation for eight periods of approximately 24 hours each. These studies provide over 650 individual determinations of radon concentration measured during a wide variety of meteorological conditions, from clear days with high radiation and relatively weak winds to cloudy days of low radiation and relatively high winds. Information presented indicates general features of radon concentration: 1) highest concentrations near the soil, the source, 2) maximum concentrations at night with the maximum near the soil occurring about 3 hours before the maximum at 16 meters, 3) minimum values at all leveis near midday, 4) almost constant concentration with elevation, indicating good mixing during morning hours, and 5) the increase of concentration at ground level ahead of those aloft with the approach of evening.

Average 24-hour exposure at human breathing level, between 1 and 4 meters, varies between 0.259 and 0.301 picocuries per liter at the Argonne National Laboratory site.
\end{abstract}

\section{Introduction}

All topsoil contains trace amounts of uranium-238, a radioactive element. One of the daughters which results from its decay is radon-222. This gas with a 3.8 day half-life is, therefore, also present in the soil and escapes to the atmosphere as a result of several processes including diffusion, evaporation of soil moisture in which radon is dissolved and exhalation due to temperature or pressure changes. It is the purpose of this paper to report on the distribution of radon in the atmosphere with height and time.

An initial study of this type conducted at the Argonne National Laboratory was reported by Moses et al. (1960) and included data for three 24-hr periods. A second study included five more 24 -hr periods and with the first three provides the basis for this paper. The data include a total of 650 observations of radon concentration in the atmosphere.

The rate of injection of radon into the bottom of the atmosphere is believed to be somewhat more uniform than that for pollen (Sheldon and Hewson, 1959), auto exhaust, domestic heating, or industrial release. The rate of injection of all of the latter is either intermittent or cyclic. As a consequence of the more uniform rate of injection of radon, it is expected that atmospheric concentrations observed are more readily studied as functions of meteorological parameters.

While the data provide an insight regarding the relationship of the variables, it is recognized that the information is limited by, 1) the small number of sam-

1 Resident Research Associate, Summers 1960, 1961 and 1965, and Professor of General and Sanitary Engineering, University of Illinois, Urbana. ples, 2) the use of only one geographical location, 3) the collection of samples during a limited time periodthe late spring and summer, and 4) the limited height of the atmospheric layer above the earth.

\section{Experimental methods}

Data were collected during 24 -hr periods on the following days : 20-21 May 1958 ; 16-17 July $1958 ; 27-28$ August $1958 ; 8-9,15-16,23-24$ June $1960 ; 28-29$ July 1960; 4-5 August 1960. During the first three tests (Moses et al., 1960), data were taken every hour on the hour. For the second group of tests, effort was made to standardize data collection at $0100 \mathrm{CST}$ and every $1 \frac{1}{2}$ hours thereafter, a sequence that provided 16 observations in a day. When averages for all eight tests were prepared, adjustments of no more than $30 \mathrm{~min}$ were required.

Sampling sile. Samples and observations for the first group of three tests were made using the $46 \mathrm{~m}$ meteorological tower at the Argonne National Laboratory, Argonne, Illinois. For the latter group of five, both this tower and a portable 16.5 -m aluminum tower were used (see Fig. 1). The ground around the towers (within $300 \mathrm{~m}$ ) is fairly level (Moses and Willet, 1954), the slopes are gradual, and elevation changes are limited to $\pm 2.1 \mathrm{~m}$, except for a steepening descent toward a ravine to the southeast. The $300-\mathrm{m}$ circle is almost without trees, although a small clump of 6-m samplings stands in a shallow hollow about $38 \mathrm{~m}$ to the north, and a line of similar trees runs down the slope to the southeast. In the southwesterly direction, the nearest trees, full grown oaks, are 380 to $430 \mathrm{~m}$ away. The ground cover of coarse grass and weeds was mowed 


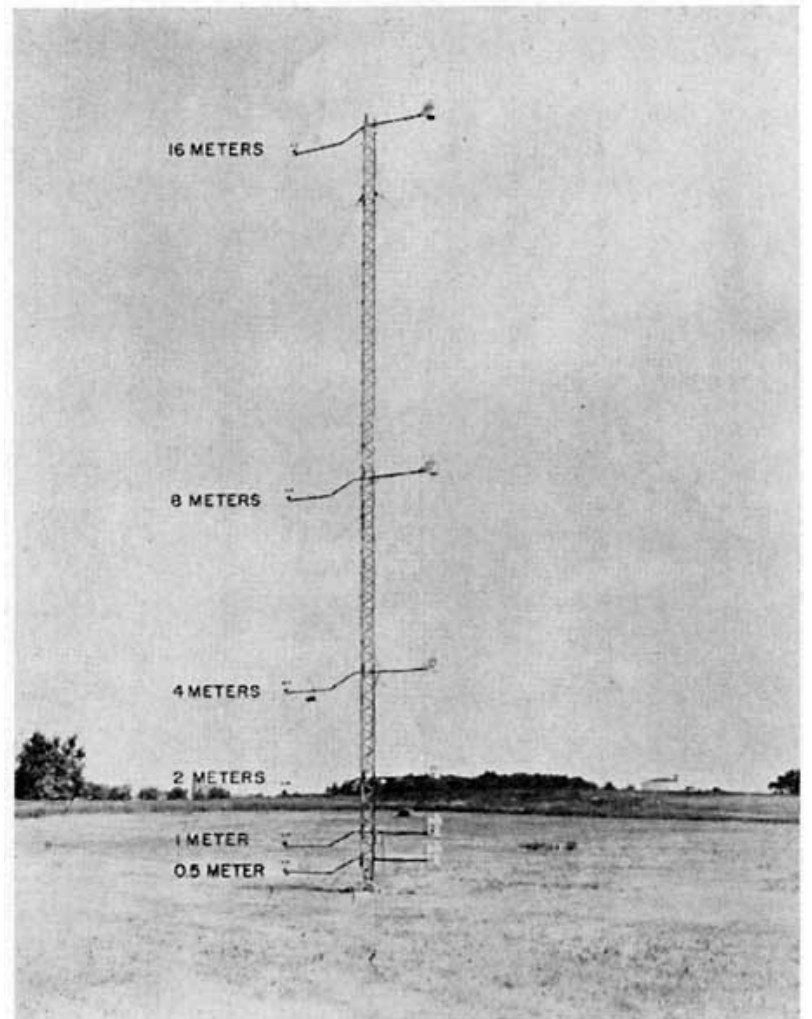

Fig. 1. The 16.5-m portable meteorological tower.

regularly and was 4 to $16 \mathrm{~cm}$ in height within $30 \mathrm{~m}$ of the towers. At $90 \mathrm{~m}$ WSW of the $16.5-\mathrm{m}$ tower was the 46-m tower of open steel-work construction and at about $185 \mathrm{~m}$ west was the Meteorology Building, a gable-roofed structure, $4.3 \mathrm{~m}$ high and about $9 \mathrm{~m}$ wide as viewed from the towers.

Radon, wind, and temperature measurements. The sampling and observing program for the first three tests is described by Moses et al. (1960). Elevations at which samples were collected or observations made during the 5-test series included one between the surface and $1 \mathrm{~cm}$ above the surface, and at $0.5,1.0,2.0,4.0,8.0$, 16.0 and $40.0 \mathrm{~m}$ above the ground. All measurements or samples reported represent mean values for 20 -min sampling periods centered at the reported times.

Wind-speed measurements were made using individually-calibrated, cup anemometers manufactured by C. F. Cassela \& Company, Ltd. of London (see Fig. 2). Rotation of the anemometer shaft opened and closed an electrical contact, and the total number of pulses for each counter was indicated on a register in the instrument shed. To check anemometer performance, they were placed on six poles at the same elevation above the ground, the poles being placed in a straight line approximately normal to the direction of the wind. Individual values measured were within 1 per cent of average values, for the six, in 95 cases out of 102 .

Temperature differences between adjacent measure- ment levels were determined with thermopile pairs mounted within two concentric, aspirated cylinders to protect them from the direct radiant energy of the sun or surroundings. The thermopile pairs included 12 copper-constantan thermocouples made of No. 26 B \& S gauge wire. Six junctions at the end of each pile were imbedded in paraffin located in the last $2 \mathrm{~cm}$ of closed Pyrex glass tubes $8 \mathrm{~mm}$ outside diameter and $5 \mathrm{~cm}$ long. Temperature difference measurements between adjacent levels were read and recorded every 30 sec of the 20-min sampling period. A potentiometer type recorder was used. Calibration indicated that the thermopiles were suitable for the experiment since 93 per cent of the measurements obtained fell within $0.016 \mathrm{C}$ of the National Bureau of Standard curves of electromotive force vs. voltage for copper-constantan and the largest variation was $0.033 \mathrm{C}$.

Meteorological measurements regularly made by the Argonne Meteorology Group were available for this study. They included wind directions and speeds to $45.7 \mathrm{~m}$ above the ground; temperature differences to $43.9 \mathrm{~m}$; dew points to $39.9 \mathrm{~m}$; soil temperatures to $8.84 \mathrm{~m}$ below ground surface; atmospheric pressure; intensity of solar radiation; and net radiation flux. Equipment used to measure these have been described previously (Moses et al., 1960; Moses and Willet, 1954).

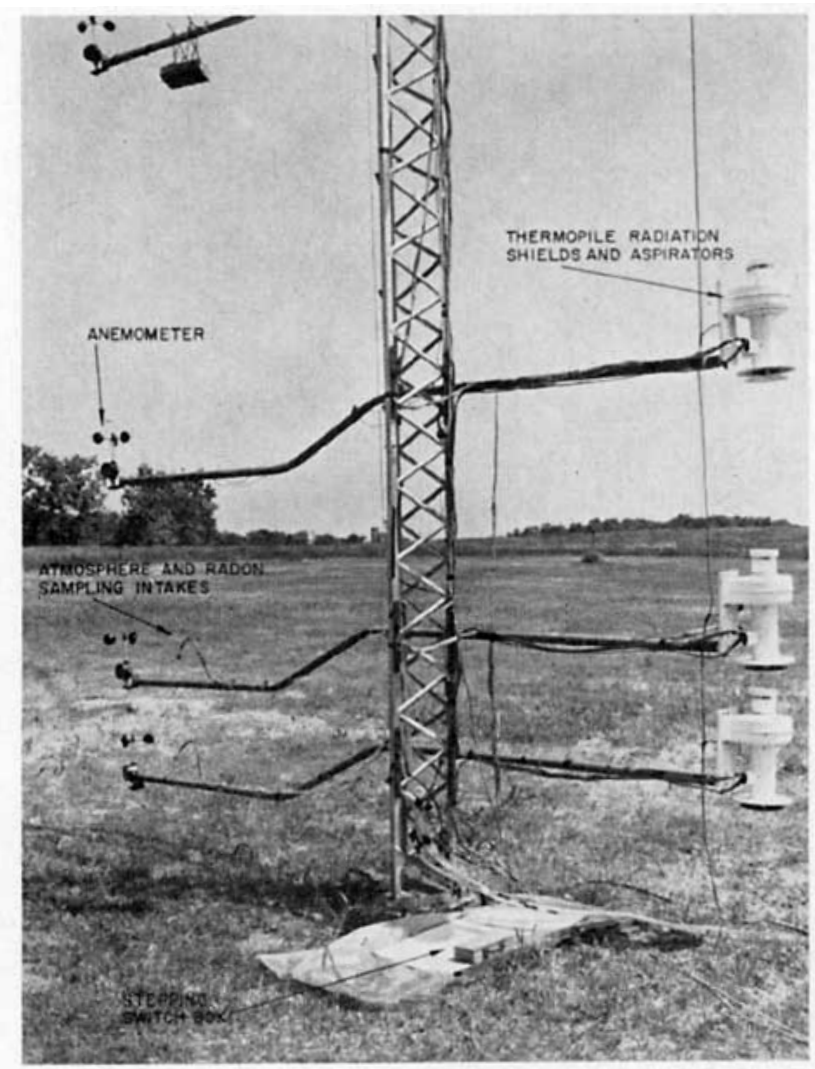

FIG. 2. The instruments and sampling inlets on the portable meteorological tower. 


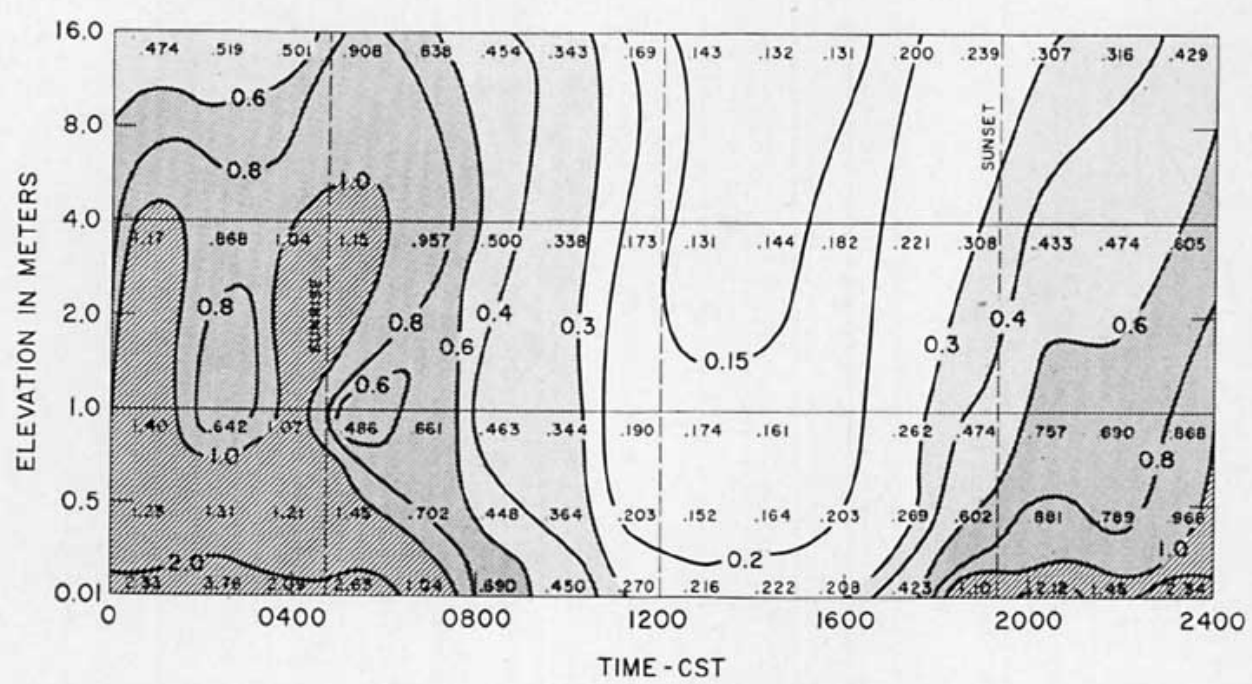

FIG. 3. Radon-222 concentration (in $10^{-12}$ curies liter $^{-1}$ ) variation with elevation and time for $28-29$ July 1960, a period with scattered to overcast clouds during daylight and clear skies, light winds, and inversion at night.

Radon-222 concentrations were determined using the method described by Lucas (1957). Briefly, this includes collection of radon-222 by adsorption on activated coconut charcoal chilled in a dry ice solution. The charcoal trap containing the sample was brought to the laboratory, where the radon sample was desorbed by heating the charcoal to $500 \mathrm{C}$. The trap was flushed several times, aged helium being used as a carrier, and the radon-helium mixture was pumped into an evacuated counting bottle, covered at one end by a quartz glass window and lined with a silver-activated zinc sulfide scintillation material. After transfer, the sealed bottle was allowed to stand about two hours during which short-lived radon decay products approached equilibrium with the parent radon-222. The radon content was determined by placing the counter bottle window in contact with the window of a photomultiplier tube, covering the assembly with a light tight shield, and counting alpha-scintillations for a measured period of time. Corrections for radon decay during the intervals between collection, transfer, and counting were made. The volume of air handled was measured with wet-test meters manufa-tured by the Precision Scientific Company, and in all cases the volume was corrected to standard temperature and pressure.

\section{Discussion}

Although eight 24 -hr periods of data represent a rather limited number of samples, the eight periods present a variety of normally occurring meteorological regimes. At one extreme is a cloudless condition with strong incoming radiation during the day and pronounced outgoing radiation at night producing a marked inversion, while at the other is an overcast situation with greatly attenuated incoming radiation during the day and with strong winds, good vertical mixing, and weak or no inversion conditions at night. It is expected that a majority of the conditions observed during the spring and summer periods are between these extremes.

Distribution of radon under the two different meteorological regimes. The cloudless situation is represented by the data for 28-29 July 1960, shown in Figs. 3 and 4 while the cloudy regime with strong winds is illustrated by the data for 23-24 June 1960, in Figs. 5 and 6.

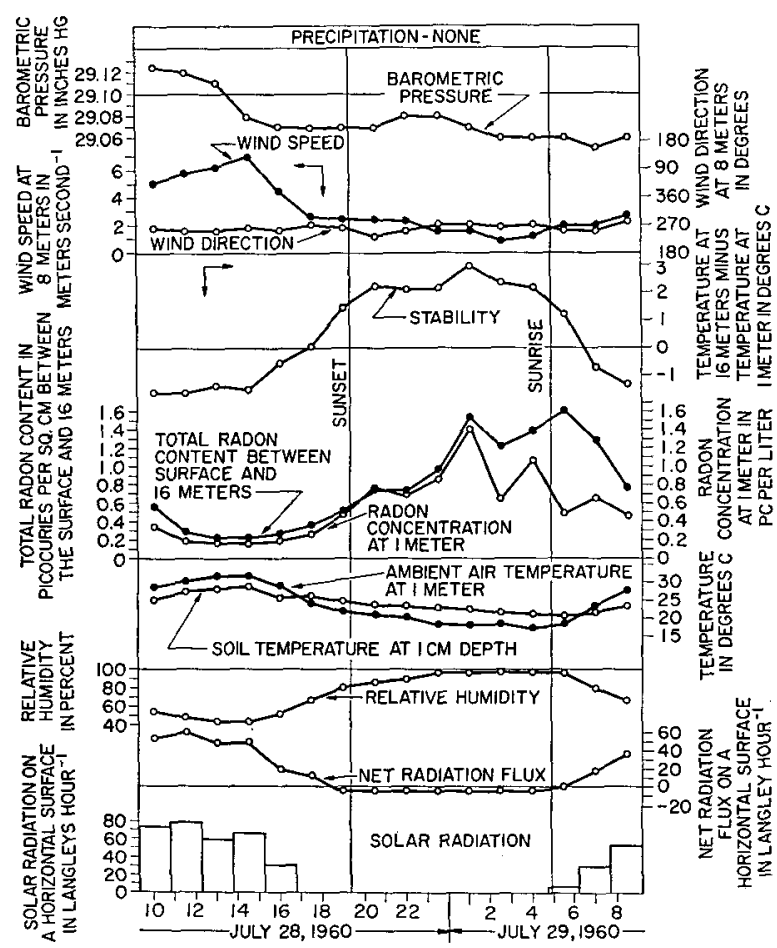

Fig. 4. Radon-222 concentrations and related meteorological variables for 28-29 July 1960. 


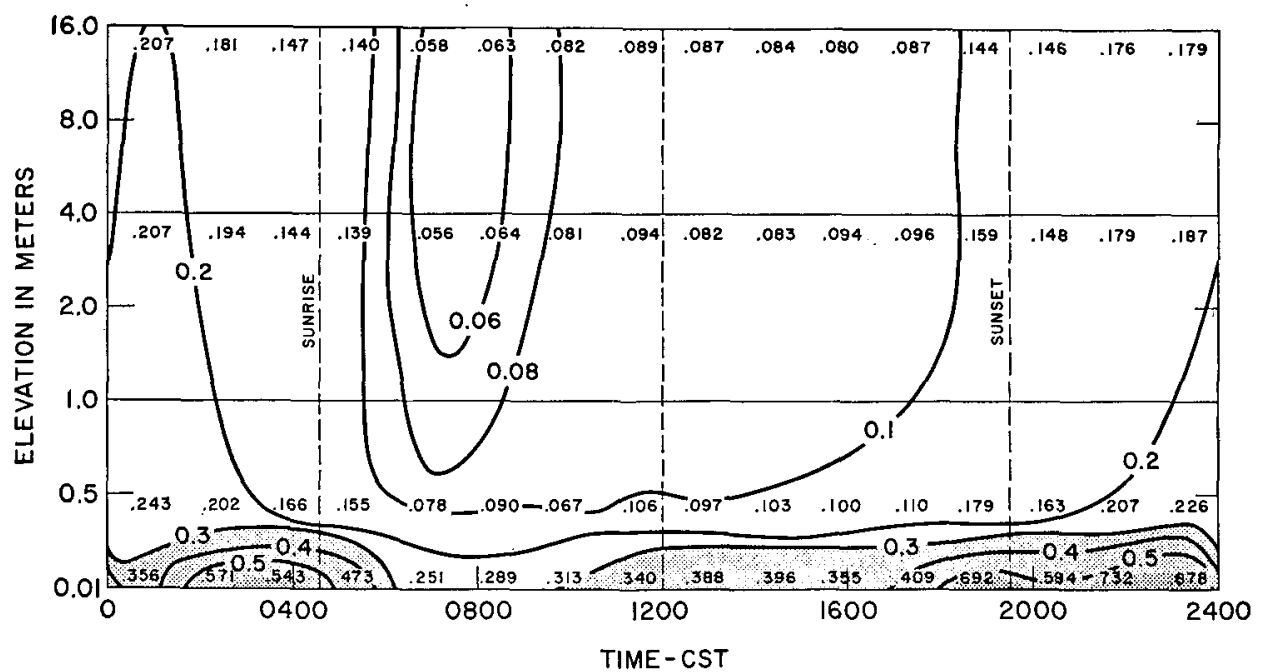

FIG. 5. Radon-222 concentration (in $10^{-12}$ curies liter ${ }^{-1}$ ) variation with elevation and time for 23-24 June 1960, a period with overcast skies during daylight and relatively high wind speeds with a weak inversion at night.

Figs. 3 and 5 show radon concentration on a heighttime plane while Figs. 4 and 6 show the associated meteorological conditions.

The two radon concentration diagrams have several common characteristics. Highest concentrations are observed next to the ground, the source. Maximum concentrations occur during the night and minimum concentrations during the day. Late morning radon concentration profiles show little variation with height

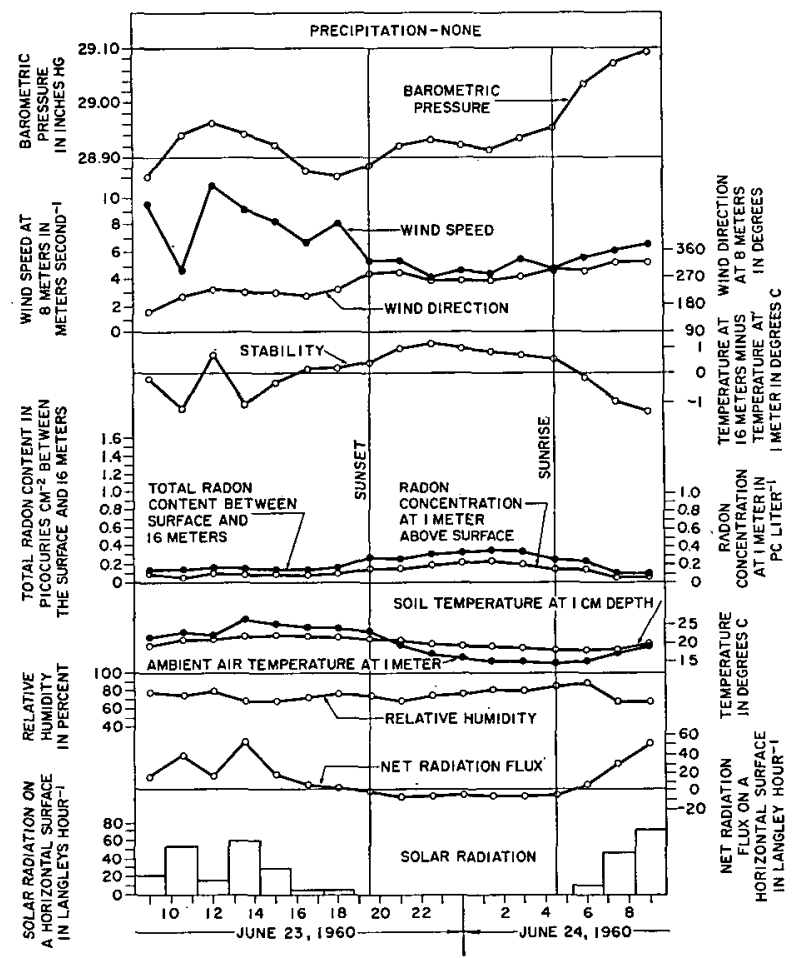

FIG. 6, Radon-222 concentrations and related meteorological variables for 23-24 June 1960. but in the early evening concentrations increase more rapidly near the ground than above as shown by the slanting isopleths.

Fig. 3 exhibits greater concentrations at all times and elevations than does Fig. 5. In Fig. 3 the maximum concentration at the ground was observed at $0230 \mathrm{CST}$ while the maximum at $16 \mathrm{~m}$ occurred three hours later, shortly after sunrise. This illustrates the inverse fumigation condition (Moses el al., 1960). The weakest concentrations were observed at about 1300 CST. While the weak concentrations observed in Fig. 5 may be attributed in part to the strong winds with pronounced mechanical turbulence and good vertical mixing of materials in the lower atmosphere, they may also be due to a reduced rate of emanation of radon- 222 from the soil due to the presence of soil moisture. Rain fell on three days preceding this test. On the morning of 20 June, the amount was 0.05 inch. In the early afternoon of June 21st, another 0.05 inch of rain was added, while on the $22 \mathrm{nd}$, steady rain from 0900 to 1500 CST provided an additional 0.20 inch. In Champaign County, 'Illinois, approximately 120 miles to the south, the same soil when moist, 0.17 to 0.18 air void fraction, ${ }^{2}$ releases about one-third the emanation that it does when dry, 0.35 to 0.45 air void fraction (Pearson, 1965). It has been suggested, also, that rising atmospheric pressure will inbibit release of radon (Evans, et al., 1962). Fig. 6 shows this to be occurring during the June test. Maximum concentration reached near the surface on the 23-24 June test was $0.732 \times 10^{-12}$ curies liter-1 compared to the $3.78 \times 10^{-12}$ curies liter ${ }^{-1}$ of the 28-29 July test. Also the daylight minimum of the June test occurring at 0700 CST was less than half the minimum for the other test occurring near 1430 CST.

2The term "air void fraction" is used to indicate the fraction of total soil volume occupied by soil gases. 


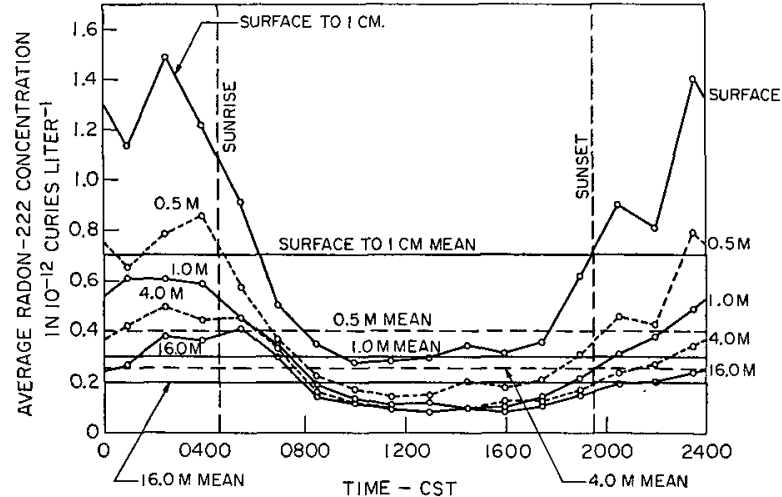

Fig. 7. Variation of mean concentrations of radon-222 with elevation and time for eight 24 -hr periods and average $24-\mathrm{hr}$ concentrations.

Average tiwe-height relationships to radon concentration. In the above section, the data taken in two individual series are presented, while in this section, averages of eight sets of samples, each taken over about 24 hours, are used. Five of the eight days when tests were run were like the one presented in Figs. 3 and 4, i.e., high incoming radiation during the day and high outgoing radiation at night, while three were similar to those shown in Figs. 5 and 6, where high wind conditions and cloudiness resulted in distributions of relatively low radon concentrations. Such a body of data may have a bias toward the clear day regime and is not presented as typical of a climatic average of radon. However, the data give an indication of radon behavior in the atmosphere and are presented with recognized limitations in mind.

If average concentrations for the eight tests are presented in the same fashion as Fig. 3, essential features are quite similar, i.e., the high buildups in the early morning hours near the ground, the inverse fumigation just after sunrise (the vertical lines representing weak vertical concentration gradients or very good mixing during morning hours), the minimum concentrations around noon or shortly thereafter, and in the evening the lag in the buildup in the upper levels after it has occurred near the ground, resulting in sloping isopleths as may be seen in the right side of Fig. 3 .

Fig. 7 presents the same data but the average radon concentration is presented as the ordinate and the time as the abscissa. The isopleths are lines of constant elevation. Fig. 7 points out strikingly the time rate of change of the radon concentration at various times of the day. Also plotted on this figure are the average values for each level based on all of the data available. It is clear from this diagram that the average radon concentrations at the breathing level, i.e., about 5 feet, if measured during the daytime, would provide values that were appreciably lower than those for the total 24-hr period or for the night hours.

In Fig. 8 is presented the radon concentration as a function of height for selected hours. Alternate observa-

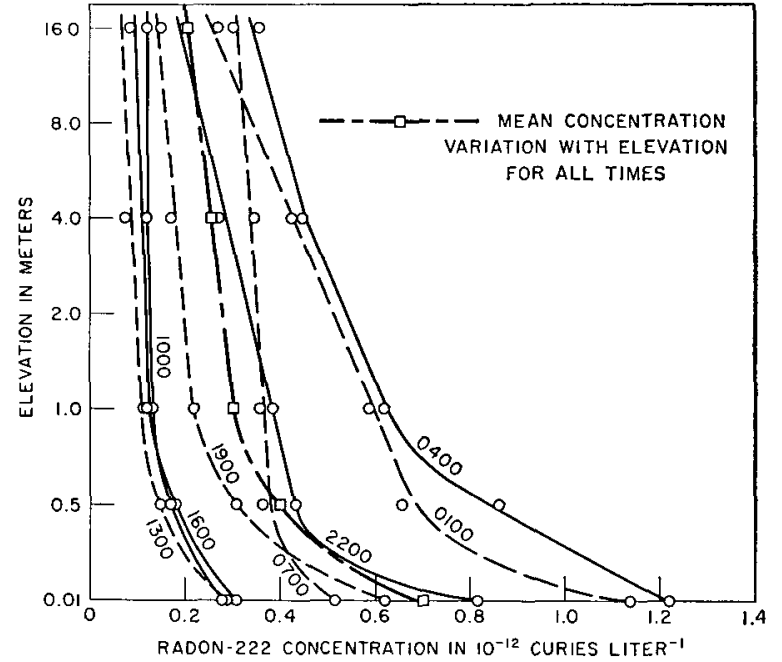

Fig. 8. Average radon-222 concentration variation with time and elevation and mean concentration variation with elevation for all times (CST).

tions are shown in this figure to avoid confusing clutter. The series of times presented does not include the daytime and nighttime extreme curves which are shown on the next figure. The dashed line with squares of Fig. 8 represents the average of all the data for each level and, therefore, represents an average profile of radon concentration. Besides showing the vertical gradient, this chart shows quite markedly that the diurnal spread in values of radon concentration is large in the lower levels and converges to a substantially smaller range at $16 \mathrm{~m}$. Each point shown on this graph represents an average of approximately eight observations. Thus, Figs. 7 and 8 emphasize different features of the radon time-height distributions and taken to-

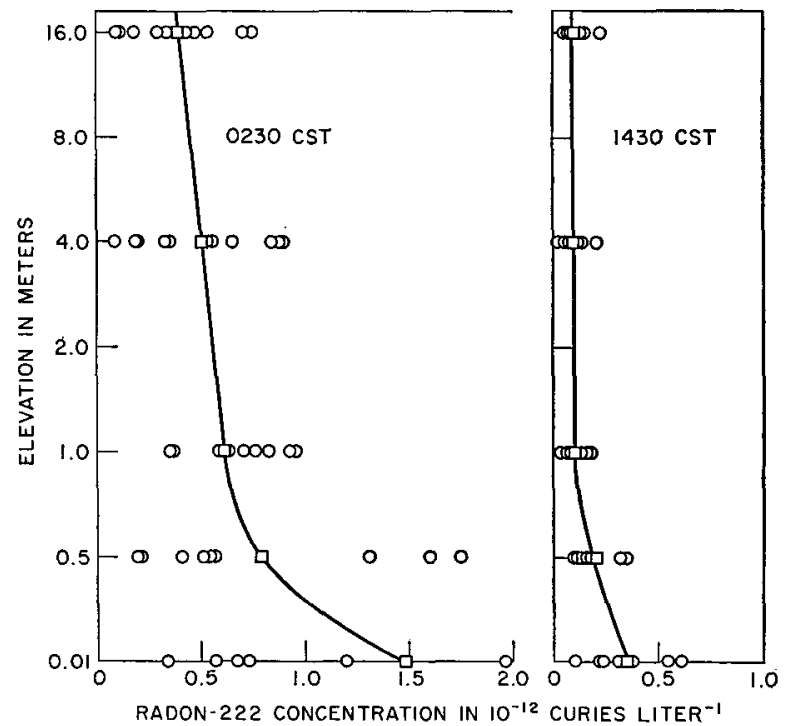

FIG. 9. Individual radon concentrations measured at various elevations at 0230 and 1430 CST and a mean curve for the times indicated. 


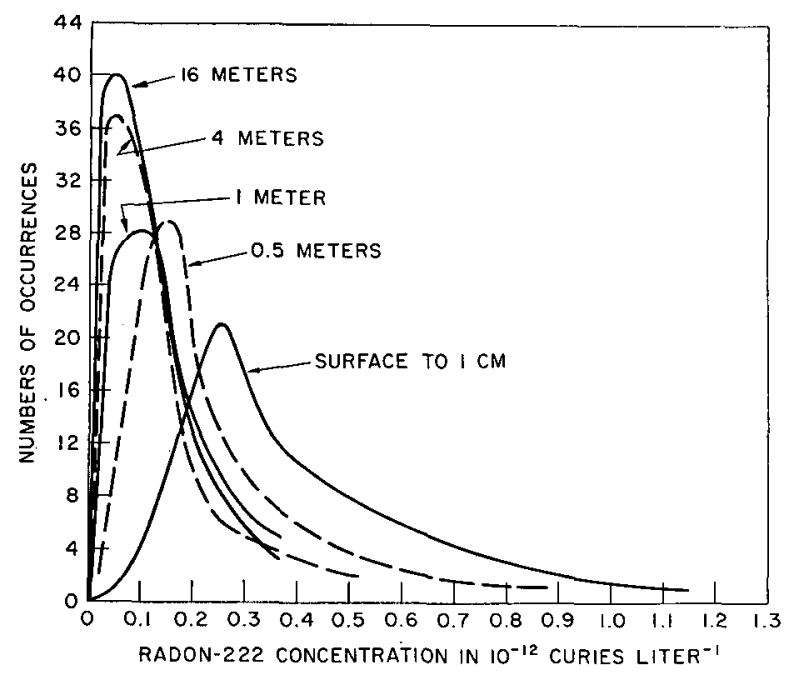

FIG. 10. Frequency distributions of nighttime radon-222 concentrations from $1830-0500$ CST.

gether provide a more complete picture of the interrelationships involved.

The curves shown in Fig. 9 represent eight test averages for the times when lowest and highest concentration profiles were observed, $1430 \mathrm{CST}$, when radon concentration is at a minimum, and $0230 \mathrm{CST}$, when concentrations are relatively high. Each point shown in this figure represents a single measurement at the time indicated. The dispersion of the data and the difference in dispersion of data points for the two times presented, are interesting features of Fig. 9.

Frequency distributions of radon concentration at various heights. To further illustrate how radon varies with height, frequency distributions of the observations for the nighttime hours, 1830 to $0500 \mathrm{CST}$, and the daylight hours, 0500 to $1830 \mathrm{CST}$, are presented in Figs. 10 and 11, respectively. These figures show the large variability of radon concentrations near the surface as compared with those at 4 or $16 \mathrm{~m}$. Also the value of radon concentrations at the mode decreases with height. Values of the standard deviation for each level for day time and nighttime values are shown in Table 1. As is evident from the data, the standard deviation tends to decrease with height both during day and night

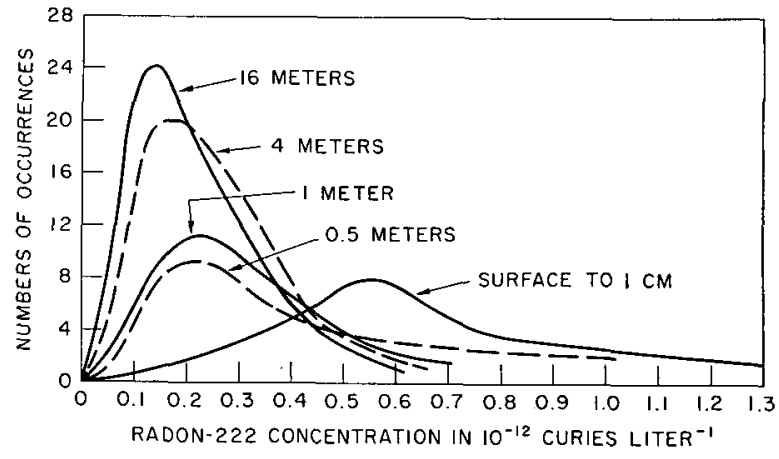

FIG. 11. Frequency distributions of daytime radon-222 concentrations from $0530-1830 \mathrm{CST}$.

but the daytime values are considerably smaller. Table 1 also summarizes the measurements by giving values for the absolute maximum, average of the maxima for the eight values, the average of all the data, average minima for the eight series of observations, and the absolute minimum for each of the levels of measurement. Of course, during the day with solar heating, vertical motions are intense and provide mixing over a relatively thick layer. During the night with the presence of inversions, this mixing is suppressed allowing the radon or any material emanating from the ground to become concentrated in the lower layers. The increase in the lower layers is shown quantitatively by these data.

Admittedly, the information provided in this report is far less than necessary to provide a complete picture. Nevertheless, conditions representing the high and low diffusion rates discussed here bracket the majority of weather conditions which may occur. Thus, this analysis may be used as a guide concerning distributions of radon as well as those of other contaminants such as pollens or auto exhausts which may be injected into the lower atmosphere. The same atmospheric processes operate in all of these cases.

\section{Radon-222 in the environment}

Although this paper has emphasized the behavior of radon-222 in the lower atmosphere under varying atmospheric conditions, it also provides information

TABLE 1. Radon concentrations (in picocuries per liter) at various elevations at Argonne National Laboratory in late spring and summer 1958 and 1960.

\begin{tabular}{|c|c|c|c|c|c|}
\hline & \multirow{2}{*}{$\begin{array}{l}\text { Surface to } \\
0.01 \mathrm{~cm}\end{array}$} & \multicolumn{4}{|c|}{ Elevation of observation in meters } \\
\hline & & 0.5 & 1.0 & 4.0 & 16.0 \\
\hline Maximum observed & 3.930 & 2.429 & 1.400 & 1.170 & 0.908 \\
\hline Average maximum & 1.732 & 0.957 & 0.764 & 0.570 & 0.449 \\
\hline Overall average & 0.705 & 0.407 & 0.301 & 0.259 & 0.204 \\
\hline Average minimum & 0.177 & 0.101 & 0.084 & 0.090 & 0.078 \\
\hline Minimum observed & 0.103 & 0.067 & 0.032 & 0.018 & 0.019 \\
\hline Daytime mean and standard deviation & $0.385 \pm 0.214$ & $0.234 \pm 0.168$ & $0.181 \pm 0.153$ & $0.179 \pm 0.197$ & $0.164 \pm 0.164$ \\
\hline Daytime median & $0 . \overline{3} 3$ & 0.18 & 0.14 & 0.11 & 0.11 \\
\hline Nighttime mean and standard deviation & $1.065 \pm 0.869$ & $0.636 \pm 0.534$ & $0.454 \pm 0.297$ & $0.339 \pm 0.243$ & $0.261 \pm 0.154$ \\
\hline Nighttime median & 0.72 & 0.46 & 0.38 & $0 . \overline{27}$ & $0 . \overline{22}$ \\
\hline
\end{tabular}


regarding concentrations of this material and the consequent exposure of plants and animals residing in the bottom $16 \mathrm{~m}$ of the atmosphere. The soil emission rate of the Argonne National Laboratory site, 56.8 \pm 5.4 $\times 10^{-18}$ curies $\mathrm{cm}^{-2} \mathrm{sec}^{-1}$ when the soil was very wet, is comparable to many others studied; likewise, the emanating radium-226 content of the soil, 0.690 picogram per gram of dry soil, at this site has been shown to be within 10 to 15 per cent of that for other locations in central United States (Pearson, 1965). As radon is supplied to the atmosphere at a very nominal rate, concentrations observed at the breathing level for humans provide a guide to exposure to this radioactive material. The data in Table 1 show that the variation of concentration in picocuries per liter ranges from 0.032 to 1.400 at $1 \mathrm{~m}$ and 0.018 to 1.170 at $4 \mathrm{~m}$, while the mean for $1 \mathrm{~m}$ is 0.301 and the mean for $4 \mathrm{~m}$ is 0.259 . A comparison of daytime with nighttime means at these elevations also can be made from data in the table.

\section{Summary and conclusions}

1. A wind direction change during one of the first three tests was accompanied by a marked increase in radon concentration. There were no well-defined wind direction changes during the latter five tests.

2. Large changes of radon concentration at the same elevation were observed from one sample to the next with the largest variations occurring nearest the surface. The observed concentrations systematically increased during the afternoon and evening and decreased in the morning hours. Such changes were common to all tests.

3. Average data for all eight tests show a maximum concentration near the ground near $0230 \mathrm{CST}$ and a maximum at $16 \mathrm{~m}$ about 3 hours later, i.e., shortly after sunrise. The phenomenon was observed during the first group of tests and was described as "an inverse fumigation."

4. At normal human breathing elevations, 1 to $2 \mathrm{~m}$ above the ground, the average concentration of radon222 in the atmosphere varied between 0.09 to 0.55 picocurie per liter, a 6 to 1 variation. In one of the first three tests during a period with clear skies a 24-hr variation at $6 \mathrm{~m}$ was 20 to 1 . However, for all eight tests, the average variation is only 5.5 to 1 .

5. Hourly values of ambient air temperature serve as rought indices of radon concentration for both groups of tests. However the same meteorological processes which affect temperature, such as cloudiness with its attendant effects on radiation and wind speed, also affect the rate of transfer for radon from its source, the earth, vertically through the atmosphere. For this reason one also observes a relationship between daily range of temperature and daily range of radon concentration at a constant elevation in the atmosphere.

6. The relationship between radon concentrations observed and such diffusion-pertinent meteorological variables as temperature change with elevation and wind speed continues to indicate that radon is an excellent tracer material for studying the vertical diffusion process in the atmosphere.

Acknozoledgements. The authors are grateful to Hugh G. Daubek, Frank C. Kulhanek and Gunther A. Zerbe for their help in carrying out the observations, and to Henry F. Lucas, Jr., for his advice and assistance in the radon analysis procedure.

This work was sponsored by the United States A tomic Energy Commission.

\section{REFERENCES}

Evans, R. D., H. W. Kraner and G. L. Schroeder, 1962: On-site radon in surface soils-Project Vela. Final Report AFTAC Project No. VELA T/2031/S/OSR, Edgerton, Germeshausen, and Grier, Inc., Boston, Mass.

Lucas H. F., Jr., 1957: Improved low-level alpha scintillation counter for radon. Rev. Sci. Instr., 28, 680-683.

Moses, H., A. F. Stehney and H. F. Lucas, Jr. 1960: The effect of meteorological variables upon the vertical and temporal distributions of atmospheric radon. J. Geophys. Res., 65, 1223-1238.

—, and J. H. Willet, 1954: Five-year climatological summary. Argonne National Laboratory Report No. ANL-5592.

Pearson, J. E., 1965: Radon-222, a study of its emanation from soil, source strength, and use as a tracer. Final Report USPHS Research Grant No. AP-00134, Department of General Engineering, University of Illinois, Urbana.

Sheldon, J. M., and E. W. Hewson, 1959: Atmospheric pollution by aeroallergens. Progress Report No. 3, USPHS Research Grant No. E-1379 (C). The University of Michigan Research Institute, Ann Arbor. 